\title{
An 11-year prospective study of personality $X$ parenting interactions as predictors of self-efficacy in young adults: diathesis-stress or differential susceptibility?
}

Marike H. F. Deutz ${ }^{1,2 \dagger}{ }^{\text {, Willemijn M. van Eldik }}{ }^{1,3 \dagger}$, Vera T. Over de Vest ${ }^{1}$, Ank Ringoot ${ }^{1}$, Amaranta D. de Haan ${ }^{1}$ and Peter Prinzie ${ }^{1 *}$

\begin{abstract}
Background: Self-efficacy, individuals' beliefs regarding their capacities to perform actions or control (potentially stressful or novel) events, is thought to be important for various life domains. Little however is known about its early precursors. This study examined the predictive effects of childhood personality and parental behaviors (i.e., overreactive discipline and warmth) for general self-efficacy in young adulthood. Furthermore, it was examined whether personality and parenting behaviors interacted and whether these interactions supported the diathesis-stress or differential susceptibility model. These aims were examined in an 11-year prospective study of 336 participants $\left(M_{\text {age }}\right.$ at $\mathrm{T} 1=10.83$ years, range $=9-12$ years, $53.9 \%$ girls). Personality and parental behaviors were reported at $\mathrm{T} 1$ by both mothers and fathers, whereas self-efficacy was self-reported at T2 11 years later. Hypotheses were tested in Mplus using multilevel structural equation modeling.

Results: Results revealed that (only) emotional stability, and not parenting, predicted higher self-efficacy 11 years later. Benevolence functioned as a susceptibility marker in the association between overreactivity and self-efficacy.

Conclusions: The results show that childhood emotional stability is an important long-term predictor of self-efficacy, even into emerging adulthood. Moreover, the integration of individual differences in models of parenting effects may further improve our understanding of early adults' adjustment.
\end{abstract}

\section{Introduction}

Self-efficacy is a key construct in multiple fields of psychology, including developmental, health and personality psychology $[1,2]$. It refers to individuals' beliefs regarding their capacities to perform actions or control (potentially stressful or novel) events that impact their lives $[2,3]$.

\footnotetext{
*Correspondence: prinzie@essb.eur.nl

${ }^{\dagger}$ Marike H. F. Deutz and Willemijn M. van Eldik shared first authorship

1 Department of Psychology, Education and Child Studies, Erasmus

School of Social and Behavioural Sciences, Erasmus University Rotterdam,

PO Box 1738, 3000 DR Rotterdam, The Netherlands

Full list of author information is available at the end of the article
}

Self-efficacy is thought to be an important aspect of functioning in various life domains such as academic achievement, life satisfaction, mental well-being, and a successful school-to-work transition [2, 4-7]. Although self-efficacy can be task- or domain-specific (e.g., academic self-efficacy), it can also be conceptualized as a broad and stable sense of individuals' confidence in capabilities to master challenges across a wide range of demanding or novel situations and is then commonly referred to as 'general selfefficacy' $[1,2]$. Despite the importance of self-efficacy for general functioning, relatively little is known about individual and proximal contextual factors that affect its development. 
According to Bandura's self-efficacy theory [3], self-efficacy is influenced by interactions between individual and environmental factors. Empirical evidence of prospective relations among individual and environmental factors and self-efficacy however is scarce. Therefore, the current study has the following two (overarching) research aims. First, we aim to examine prospective relations between personality and parental behaviors in childhood (9-12 years) and self-efficacy 11 years later in early adulthood. Personality was selected as it is considered a key construct to describe relatively stable individual differences $[8,9]$. Warmth and overreactive parenting were selected as these are two key parental behaviors that fall into the dimensions of support and control respectively $[10,11]$, and which, moreover, are potentially malleable environmental factors. Second, we aimed to examine whether personality moderates associations between childhood parenting behaviors and early adult selfefficacy. Specifically, we empirically tested whether the diathesis-stress (i.e., certain personality traits are linked to vulnerability and later problems in adverse environments [12]) or the differential susceptibility [13] model of person-environment interaction (i.e., these personality traits are susceptibility factors, predicting problems in adverse environments but also better outcomes in good environments) was supported.

\section{Parenting and self-efficacy}

Parents are thought to play an important role in self-efficacy, even when the child is an emerging adult and might no longer reside with his or her parents (see e.g., [14]). Emerging adulthood is a time in which great (potential stressful) changes in autonomy development occur and other important social contexts, such as the peer group, take a more eminent place in the individual's life [15]. The self-determination theoretical framework [16], which is closely aligned with self-efficacy theory [17], is useful in describing how parenting can affect self-efficacy. According to the self-determination theory, all individuals have basic psychological needs for autonomy, relatedness, and competence, of which fulfillment is essential to wellbeing. Self-efficacy is often used as a proxy for competence as these concepts are thought to be intertwined [15, 17]. Whereas all needs can be either promoted or hampered by environmental factors, competence is thought to be a direct outcome of parenting behaviors [15].

Parenting behaviors are often classified under two broad parenting dimensions characterizing the quality of the parent-child interaction (i.e., warmth, support) and the nature of parental discipline (control) $[10,18]$. In the current study, we focus on warmth (i.e., support) and overreactive (i.e., controlling) parenting as two key parenting behaviors that are both expected to impact self-efficacy [19]. Warmth refers to behaviors of acceptance, nurturance and affection [20] and is generally recognized as a central influence in early socialization [21]. If parents display warm and supportive behavior towards their child, this gives the child a secure base from which exploration can occur, and to which the child can return when challenging situations come about. Warmth is thus thought to foster autonomy development and, in turn, competence/self-efficacy [22, 23]. Overreactive parenting, on the other hand, refers to controlling, aversive, and intrusive reactions to child problematic behaviors $[21,24]$. When parents show overreactive discipline, this might hinder self-efficacy development, since such parenting behavior restrict the child's autonomy, which can lead to doubts about one's feelings of competence [23]. Such parenting behaviors may ultimately lead to children fearing to do something wrong, and therefore potentially missing important learning experiences in which they could have experienced feelings of competence [23].

Several cross-sectional studies in diverse samples have demonstrated links between parenting behaviors and general self-efficacy in childhood, adolescence and young adulthood. These studies showed relations between lower general self-efficacy and lower support or autonomysupportive parenting [15, 23, 25], higher psychological control [23, 25], and more helicopter, or (over-)controlling parenting [15, 26-28]. As most of these studies were conducted in specific populations such as college students [15, 26-28], Iranian-American adolescents [23], or immigrant families [25], results cannot be generalized to the (Western) population. For example, in Iranian adolescents authoritarian paternal parenting was unexpectedly positively related to general self-efficacy, which the authors explain with the collectivist culture in Iran where authoritarian parenting is not necessarily considered an ineffective parenting style [29].

Unfortunately, prospective research on links between parenting behaviors and general self-efficacy is scarce, and especially research regarding the long-term impact of parenting on young adults' general self-efficacy is lacking. As parenting behaviors are partly malleable, this knowledge could have implications for intervention programs focusing on strengthening young adults' well-being, including general self-efficacy. In this study, we therefore examined prospective associations between two important parenting behaviors, warmth and overreactive discipline, and general self-efficacy in young adulthood.

\section{Diathesis-stress and the differential susceptibility model}

Personality, which refers to tendencies to think, feel and behave in certain consistent ways [30], is a key individual factor affecting functioning and has been shown to be related to (general) self-efficacy. Although mostly 
examined in adult samples and at one time point, (G) SE appears to be related to personality, especially to the traits of (lower) neuroticism, and (higher) extraversion and conscientiousness (e.g., [31-34]). With regard to children, highly conscientious children are thought to have more willingness to work hard, are better able to focus on goals and hold greater beliefs that they can achieve desired outcomes, increasing self-efficacy. Children higher in neuroticism are more emotionally unstable, less confident and have more trouble making decisions. They are often more anxious, which can suppress or decrease self-efficacy [35]. More extraverted children are thought to show more initiative and assertiveness and more general confidence in their abilities, and they also elicit more positive responses from others, which can increase selfefficacy [33, 34].

Moreover, in addition to these direct associations, ecological transactional models emphasize that integrating parent and child effects into one theoretical model may better explain heterogeneity in adjustment than a consideration of these effects in isolation [36]. Personality is thought to be an important individual factor that shapes individual's sensitivity to environmental influences. Studies examining personality as a moderator of environmental factors on individual outcomes, have shown for example that personality and parenting interact in predicting social adjustment in school [37], aggression and delinquency [38] as well as anxious and depressive problems [39]. The role of parenting in young adult selfefficacy might thus differ depending on children's personality traits, which can be described with two influential models of person-environment interactions: the diathesis-stress model and the differential susceptibility model. The diathesis-stress model states that children that posit certain individual factors, such as personality traits, are more vulnerable as they show worse outcomes in more adverse environments $[12,40]$. The differential susceptibility expands this view, because it adds a positive notion and pinpoints the advantages of certain traits in the context of supportive environments [13, 41]. The differential susceptibility model posits that children with certain individual traits not only show worse outcomes in more adverse environments, but also better outcomes in more optimal environments. They are thus not vulnerable, but more susceptible to the environment than others, as they are affected by the environment both for better and for worse [40].

\section{The current study}

Summarizing, the current study aims to examine relations between parenting in childhood and child personality and self-efficacy in young adulthood, as well as the potential moderating role of personality in associations.
We add to existing knowledge by employing a prospective design spanning 11 years, thereby extending previous research on parenting and self-efficacy that is mostly cross-sectional. Mothers and fathers reported on their child's personality and their own warmth and overreactive discipline when the child was aged 9-12 years, and self-efficacy was self-reported 11 years later during early adulthood (20-23 years). Based on the literature, our hypotheses are that [1] parenting behaviors, specifically less warmth and more overreactive discipline, predict lower self-efficacy (e.g., [22, 23]), (2) personality, especially higher neuroticism and lower extraversion and conscientiousness predict lower self-efficacy (e.g., [31-34]), and (3) that associations between parenting behaviors and self-efficacy would depend on child personality traits, either for children with a more vulnerable personality profile (diathesis-stress) or 'for better and for worse' (differential susceptibility). Specifically, according to both the diathesis-stress and the differential susceptibility models, low warmth and high overreactive discipline (reflecting a more adverse environment) would be associated with lower young adult self-efficacy for children with less optimal personality traits. The differential susceptibility model additionally states that high warmth and low overreactive discipline would also be associated with higher young adult self-efficacy for children with less optimal personality traits.

By examining if certain personality traits make children either more vulnerable or more susceptible to parental influences on self-efficacy, we extend knowledge on how self-efficacy is shaped. Examining both models statistically can lead to more fine-grained knowledge on associations between parenting, personality and self-efficacy and more refined implications for promoting self-efficacy. Ultimately, this knowledge could aid in potentially identifying children that could benefit from targeted interventions aimed at boosting self-efficacy, which in turn could positively affect functioning across different domains.

\section{Method \\ Participants and procedure}

This study is part of the ongoing longitudinal Flemish Study on Parenting, Personality, and Development (FSPPD; e.g. [42]). In 1999, a proportional stratified sample of elementary-school-aged children attending regular schools in Flanders (Belgium) was randomly selected. Strata were constructed according to geographical location (i.e., province), age and gender. All participants provided written informed consent and all procedures were approved by the board of the KU Leuven. At the first assessment in 1999, 674 families participated of which 92.5\% were two-parent families, $50 \%$ of the children were boys, and all children had the Belgian nationality. 
In this study, data of the 4th (T1: 2004) and 8th wave (T2: 2015) were used because these waves contained the measures of interest. At T1, families received questionnaires per mail and at T2 questionnaires were distributed online. We included all participants with data of at least one informant on personality and parenting at $\mathrm{T} 1$ and complete data at T2 for self-reported self-efficacy. This resulted in a sample of $N=336$ children ( $46.1 \%$ boys and $53.9 \%$ girls). The recruited sample initially committed to a four-year study and over the 16-years span of the main reasons for dropping out were (1) no longer willing to participate and (2) loss of contact information, mainly during the transition to emerging adulthood including moving to independent homes.

At Time 1, we used both parents (if available) as informants to measure personality and parenting. Selfefficacy was measured using self-report at Time 2. At Time 1 , mean age of the children was $M=10.83$ years (range 9.00-12.92 years). The mean age of the parents was $M=40.20$ years (range 30.08-54.92) for mothers and 42.01 years (range 31.67-63.67) for fathers. At Time 2, 11 years later, the participants were aged 20.0023.92 years and the mean age was 21.83 years. Percentages of various educational levels were as follows for mothers and fathers, respectively: elementary school $(0.6 \%, 2.4 \%)$, secondary education $(33.0 \%, 39.6 \%)$, nonuniversity higher education $(50.9 \%, 35.4 \%)$, university $(14.6 \%, 20.5 \%)$, missing $(0.9 \%, 2.1 \%)$. At T2, $62 \%$ of the emerging adults lived with their parents, $23.1 \%$ lived in a shared student home, $9.9 \%$ had an independent living situation, and $4.8 \%$ described their situation as different.

Missing data analysis was conducted, ${ }^{1}$ showing that participants who participated at both $\mathrm{T} 1$ and $\mathrm{T} 2$ $(N=336)$ and participants who only participated at $\mathrm{T} 1$ $(N=176)$ did not differ statistically from each other on age or measures of parenting and personality, except for father reported extraversion $\left(M_{\text {incomplete }}=3.24\right.$ $(S D=0.33), M_{\text {complete }}=3.16(S D=0.33), t(462)=2.56$, $p=0.013)$ and mother reported imagination $M_{\text {incom- }}$ plete $=3.35 \quad(S D=0.46), \quad M_{\text {complete }}=3.45 \quad(S D=0.45) \quad(t$ $(465)=-2.21, p=0.027)$. Little's missing completely at random test indicated that data were missing completely at random $\chi^{2}(474)=451.83, p=0.761$.

\section{Measures}

\section{Parental overreactivity}

Maternal and paternal overreactive discipline was measured at T1 using parents' self-reports of the Dutch translation of the Parenting Scale [43, 44]. The Overreactivity

\footnotetext{
${ }^{1}$ Additional attrition analysis regarding attrition from the previous data waves to our selected T1 (available upon request from the last author) showed no meaningful differences.
}

scale consists of nine items and assesses angry, frustrated, and aversive reactions to their child's problematic behavior. Items are formulated as hypothetical situations of discipline encounters (e.g., "When my child misbehaves...") followed by two opposite anchor points rated on a 7-point Likert scale (e.g., 'I speak to my child calmly''I raise my voice or yell'). Mean scores were computed. Cronbach's alphas were .77 for mother-reports and .76 for father-reports. Mother- and father-reports correlated weakly $(r=.26)$.

\section{Parental warmth}

Maternal and paternal warmth were measured at T1 using parents' self-reports of the Parenting Practices Questionnaire [PPQ; [45]). The Warmth scale consists of 11 items and assesses the extent to which parents are affectionate to their child and are involved in their child's life (e.g., 'I express affection by hugging, kissing, and holding my child'). All items are rated on a five-point Likert scale ranging from 1 (never) to 5 (always). Mean scores were computed. Cronbach's alphas were .82 for mother-reports and .85 for father-reports. Mother- and father-reports correlated weakly $(r=.34)$.

\section{Children's big five personality}

Children's personality dimensions were measured at T1 using mother- and father-reports of the Hierarchical Personality Inventory for Children (HiPIC; [46]). The HiPIC consists of 144 items and assesses 18 facets of 8 items that are grouped under five higher order domains: (1) Extraversion (32 items, e.g., 'has an excess of energy'); (2) Benevolence (40 items, e.g., 'obeys without protest'); (3) Conscientiousness (32 items, e.g., 'Likes to have things in order'); (4) Emotional Stability (16 items, e.g., 'is quick to worry about things (reversed)'), and (5) Imagination (24 items, 'Likes learning new things'). All items are rated on a five-point Likert scale ranging from 1 (barely characteristic) to 5 (highly characteristic). Cronbach's alphas for the mother- and father-reports ranged from .89 for father reported emotional stability to .94 for mother and fatherreported conscientiousness, (mean $\alpha=.92$ ). For every dimension, scores were averaged across items. Correlations between mother and father reports were high for all five factors $\left(r_{\text {average }}=.70\right.$, range $=.67$ (Benevolence, Emotional Stability and Imagination) to .79 (Conscientiousness)). Therefore, scores of mother and father reports were averaged.

\section{Self-efficacy}

Self-efficacy was measured at T2, using young adults' self-reports of the Dutch translation of the Generalized Self-Efficacy Scale [47, 48]. This questionnaire consists of 10 statements and assesses the extent to which an 


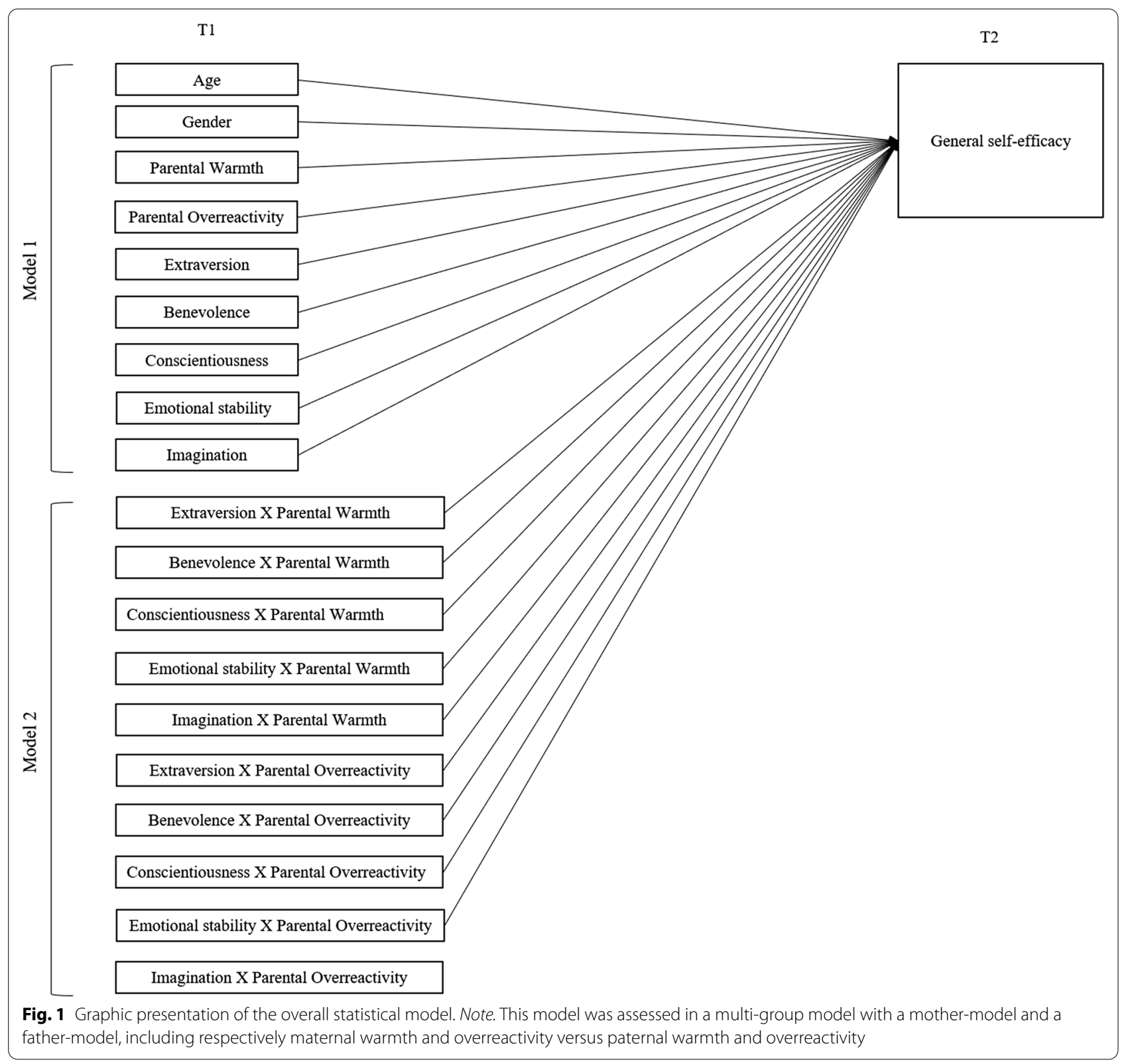

individual has optimistic self-beliefs to cope with stressors and difficult life situations (e.g., 'I always manage to solve difficult problems, if I put enough effort into it'). All items are rated on a four-point Likert scale, ranging from 1 (not at all true) to 4 (exactly true). A mean score was computed. Cronbach's alpha in the current study was .84 .

\section{Statistical analyses}

First, descriptive statistics and bivariate correlations among all variables were calculated. Then, linear regression analyses were conducted using Mplus 8.3 [49]. Age and gender of the child, and the main effects of parental warmth and overreactivity and the Big Five personality dimensions were included in the first model. The ten interaction terms of parenting with the Big Five dimensions were added in the second model (see Fig. 1). To reduce multicollinearity as well as to facilitate the interpretation of interaction effects, predictor and moderator variables were standardized before the interaction terms were computed [50]. Maximum likelihood with robust standard errors (MLR) estimation was used to account for potential nonnormality when estimating standard errors [51] and full information likelihood (FIML) was used to take into account missing data. Dependence 
Table 1 Pearson correlations, mean scores and standard deviations of all study variables

\begin{tabular}{|c|c|c|c|c|c|c|c|c|c|c|c|c|}
\hline & 1 & 2 & 3 & 4 & 5 & 6 & 7 & 8 & 9 & 10 & $M$ & $S D$ \\
\hline 1. Age in years at time 1 & - & & & & & & & & & & 10.78 & 1.13 \\
\hline 2. Overreactive discipline (M) & .01 & - & & & & & & & & & 3.06 & 0.83 \\
\hline 3. Overreactive discipline (F) & .01 & $.26^{* * *}$ & - & & & & & & & & 3.16 & 0.82 \\
\hline 4. Warmth (M) & .02 & $-.29^{* * *}$ & -.10 & - & & & & & & & 4.24 & 0.42 \\
\hline 5. Warmth (F) & -.10 & $-.18^{* *}$ & $-.12^{*}$ & $.34^{* * *}$ & - & & & & & & 3.64 & 0.57 \\
\hline 6. Extraversion & $-.11^{* *}$ & $-.12^{*}$ & $-.21^{* * *}$ & $.26^{* * *}$ & $.19^{* *}$ & - & & & & & 3.54 & 0.46 \\
\hline 7. Benevolence & .09 & $-.37^{* * *}$ & $-.32^{* * *}$ & $.25^{* * *}$ & $.26^{* * *}$ & $.17^{* *}$ & - & & & & 3.54 & 0.43 \\
\hline 8. Conscientiousness & -.04 & $-.20^{* * *}$ & $-.15^{* *}$ & $.26^{* * *}$ & $.18^{* *}$ & $.18^{* *}$ & $.36^{* * *}$ & - & & & 3.38 & 0.56 \\
\hline 9. Emotional Stability & .08 & $-.20^{* * *}$ & $-.24^{* * *}$ & $.17^{*}$ & .11 & $.47^{* * *}$ & $.33^{* * *}$ & $.33^{* * *}$ & - & - & 3.48 & 0.56 \\
\hline 10. Imagination & $-.13^{*}$ & $-.18^{* *}$ & $-.18^{* *}$ & $.24^{* * *}$ & $.26^{* * *}$ & $.43^{* * *}$ & $.17^{* *}$ & $.57^{* * *}$ & $.43^{* * *}$ & & 3.79 & 0.50 \\
\hline 11. Self-efficacy & .03 & -.09 & .04 & .01 & -.02 & $.19 * * *$ & .002 & .06 & $.28^{* * *}$ & $.19^{* *}$ & 2.90 & 0.39 \\
\hline
\end{tabular}

$M$, mother; $F$, father

${ }^{*} p<.05,{ }^{* *} p<.01,{ }^{* * *} p<.001$

of informants was accounted for by adjusting standard errors using a sandwich estimator by specifying the complex option in Mplus 8.3 [52].

To interpret significant interaction effects in terms of differential susceptibility or diathesis-stress, we conducted five post hoc analyses according to statistical recommendations outlined by Roisman et al., [53]. First, the effect of parenting was plotted as a function of the moderator (i.e., personality factor) using the JohnsonNeyman technique (J-N technique; [54,55]) to reveal the regions of significance (RoS) of personality wherein the relationship between parenting and self-efficacy was significant. The region of significance was determined by the $95 \%$ confidence interval. If the $95 \%$ confidence interval contained the value of zero, then the association between parenting and self-efficacy was not significant. The changes in magnitudes of the slope of parenting on self-efficacy are also presented in the plot for regions of significance [56]. Second, simple slopes analyses were used to estimate the magnitude of the slopes of parenting on self-efficacy at $2 \mathrm{SD}$ below and above the mean of the personality dimension $[50,53,57]$. Third, further quantification of the interaction effect in terms of diathesis stress vs. differential susceptibility was conducted by computing the "proportion affected" (PA) index and the proportion of interaction index (POI), following recommendations of Roisman et al. [53]. The PA index identifies the proportion of participants who benefit from the positive environment. Evidence for the differential susceptibility hypothesis would come from a PA index around 0.50 and support for the diathesis-stress model from a PA index of 0.00 [53]. The PoI reflects the proportion of the total area in the interaction plot that can be attributed to differential susceptibility. Values of the PoI between 0.20 and 0.80 could be interpreted as supportive of the differential susceptibility hypothesis and values close to 0.00 suggest evidence for diathesis-stress [58, 59]. Finally, to test the possibility that differential susceptibility is an artifact of imposing a linear predictor model on a nonlinear diathesis-stress phenomenon, we tested three additional models that included (parenting) ${ }^{2}$, personality X (parenting) ${ }^{2}$ and both nonlinear effects. To provide evidence for differential susceptibility, results of these models must show that neither one of both quadratic terms, nor the combination of both is statistically significant [53].

The goodness-of-fit of the model was evaluated using the chi-square test, the Comparative Fit Index (CFI) and the Root Mean Square Error of Approximation (RMSEA). A non-significant chi-square, a CFI of above 0.95 [60] and a RMSEA of below 0.08 [61] indicate a good fit.

To test possible differences between mother and father parenting, model fit was compared for two multigroup models grouped by parenting informant (i.e., mother and father). In the first model, all specified paths were freely estimated. In the second model, all specified paths were constrained to be equal. To compare model fit, the log likelihood difference test was corrected for MLR estimation using the scaling correction factor [62].

\section{Results \\ Descriptive statistics}

Means, standard deviations and correlations among study variables are reported in Table 1. Childhood extraversion, emotional stability and imagination were positively related to self-efficacy in emerging adulthood. Self-reported parenting of mothers and fathers was not significantly related to self-efficacy. Most of the personality dimensions were negatively related to maternal and 
paternal overreactivity and positively related to maternal and paternal warmth.

\section{Main effects of parenting and personality on self-efficacy}

To examine main effects in the longitudinal prediction of self-efficacy in young adulthood (aim 1), we entered the covariates age and gender, five personality dimensions and two parenting variables as predictors of GSE (Fig. 1, model 1). First, a multigroup baseline unconstrained model was established against which a model that includes equality constraints was compared. In this constrained model, direct pathways from covariates and the seven predictors to self-efficacy were constrained to be equal across mother- and father-data. The fit of the baseline model could not be estimated because this was a saturated model (zero degrees of freedom). Model fit of the constrained model was $\left(X^{2}(9)=22.87, p=0.01\right.$, $\mathrm{CFI}=0.77$, RMSEA $=0.07 \quad[0.03-0.10])$. The SatorraBentler scaled chi-square was $22.87(d f=9), p<0.01$, indicating that the model with equality constraints fitted the data significantly worse. Based on the modification indices, the effect of overreactivity on self-efficacy was freely estimated for mother and father ratings. This model indicated an adequate fit to the data $\left(\chi^{2}(8)=5.74\right.$, $p=0.68, \mathrm{CFI}=1.00, \mathrm{RMSEA}=0.00[0.00-0.05])$. The Satorra-Bentler scaled chi-square was $5.73(d f=8)$, $p=0.68$, indicating that with the exception of overreactivity (mothers: $B=-0.03 ; p=0.18$, fathers: $B=0.03$; $p=0.22$ ), effects of the covariates and direct effects of personality and parenting on self-efficacy were similar for father and mother reports (Table 2). Model results showed that emotional stability was significantly related to more general self-efficacy eleven years later $(b=0.09$, $p<0.001)$. Girls reported significantly lower self-efficacy than boys $(b=-0.08, p<0.05)$. There were no significant main effects of parenting. This model explained $12 \%$ of the variance in self-efficacy.

\section{Interaction effects of personality in relations between parenting and self-efficacy}

To examine whether personality moderated the effect of parenting on GSE in line with the diathesis stress or the differential susceptibility hypothesis (aim 2), we included ten personality X parenting interactions in Model 2 (Fig. 1). First, we tested a model in which parameters for interaction effects were freely estimated. Next, a model was tested in which parameters for interaction effects were constrained across mothers and fathers. The constrained model indicated an adequate fit to the data $\left(\chi^{2}\right.$ $(10)=9.04, p=0.53$, CFI $=1.00$, RMSEA $=0.00 \quad[0.00-$ $0.06])$. The Satorra-Bentler scaled Chi-Square was 9.04 $(d f=10), p=0.53$, indicating that estimates of interaction effects were similar for father and mother reports of parenting. Finally, although the effect of overreactivity on self-efficacy was statistically different for mother and father ratings in Model 1, these effects of overreactivity were (again) non-significant for both parents in Model 2. Therefore, in order to obtain the most parsimonious model, we tested a fully constrained Model 2 in which all direct and interaction effects were constrained to be equal in mother and father data. Fit indices showed an adequate fit to the data $\left(\chi^{2}(19)=20.38, p=0.37\right.$, $\mathrm{CFI}=0.98$, RMSEA $=0.02[0.00-0.05])$. The SatorraBentler scaled Chi-Square was $20.38(d f=19), p=0.37$, indicating that estimates were similar for father and mother reports of parenting. This most parsimonious model was selected as the final model.

Model results of the moderator analyses (see Table 2) showed one significant interaction effect: children's benevolence moderated the longitudinal effects of both mothers' and fathers' overreactivity on self-efficacy 11 years later. We plotted the region of significance for the slope of overreactivity on self-efficacy. As can be seen in Fig. 2, the effect of overreactivity on self-efficacy was not significant for children scoring between $0.9 \mathrm{SD}$ below the mean, and 1.0 SD above the mean on benevolence. Among children scoring lower than - 0.9SD on benevolence $(n=110)$, as indicated by the area where the $95 \%$ confidence band did not contain the value of zero in Fig. 2, more overreactivity was associated with lower self-efficacy. Moreover, the strength of this effect increased when scores on benevolence decreased. Simple slope analyses showed that $B(-2 \mathrm{SD})=-0.10,[-0.17$ to -0.02 ],$p<0.01$. For children scoring higher than 1.0SD on benevolence $(n=94)$, more overreactivity was associated with higher self-efficacy and the strength of this effect increased when scores on benevolence increased. Simple slope analyses showed that $B(2 \mathrm{SD})=0.10[0.02-$ $0.18], p=0.01$ ).

Further quantification of the interaction effect in terms of diathesis stress vs. differential susceptibility was conducted by computing the PA index and the POI (Roisman et al. [53]. In order to calculate the PA we identified the cross-over point, which was $-0.54(-0.027 / 0.050)$. The percentage in the sample that is differentially affected by the moderator, scoring lower than -0.54 on overreactivity (standardized) was $32.1 \%$ of the mothers and $32.3 \%$ of the fathers in the sample, providing evidence for differential susceptibility. Next, the PoI was 0.25 , which can be also be interpreted as evidence for differential susceptibility. Results of the three models with non-linear predictors indicated that none of the nonlinear predictors was significant whereas the interaction effect remained statistically significant. The final model with direct and interaction effects explained $14 \%$ of the variance in self-efficacy. 
Table 2 Model results for: main and interaction effects of parenting and personality on GSE

\begin{tabular}{|c|c|c|c|c|c|}
\hline \multirow[t]{2}{*}{ Self-efficacy } & \multirow[t]{2}{*}{$B$} & \multirow[t]{2}{*}{ SE } & \multicolumn{2}{|c|}{$95 \% \mathrm{Cl}$ for $B$} & \multirow[t]{2}{*}{$p$} \\
\hline & & & LL & UL & \\
\hline \multicolumn{6}{|l|}{ Main effects (model 1) } \\
\hline Age & .013 & .019 & -.03 & .05 & .51 \\
\hline Gender & $-.080^{*}$ & .040 & -.16 & -.001 & .047 \\
\hline Overreactivity & $-.027^{a} / .030^{b}$ & $.020 / .025$ & $-.07 /-.02$ & $.01 / 08$ & $.18 / .22$ \\
\hline Warmth & -.019 & .019 & -.06 & .02 & .32 \\
\hline Extraversion & .030 & .023 & -.02 & .08 & .19 \\
\hline Benevolence & -.026 & .024 & -.07 & .02 & .28 \\
\hline Conscientiousness & -.017 & .026 & -.07 & .03 & .51 \\
\hline Emotional stability & .092 & .026 & .04 & .14 & $<.001$ \\
\hline Imagination & .045 & .031 & -.02 & .11 & .15 \\
\hline \multicolumn{6}{|l|}{ Main effects (model 2) } \\
\hline Age & .015 & .019 & -.02 & .05 & .45 \\
\hline Gender & -.068 & .040 & -.15 & .01 & .09 \\
\hline Overreactivity & .000 & .018 & -.04 & .04 & .98 \\
\hline Warmth & -.014 & .018 & -.05 & .02 & .43 \\
\hline Extraversion & .030 & .024 & -.02 & .08 & .22 \\
\hline Benevolence & -.027 & .023 & -.07 & .02 & .23 \\
\hline Conscientiousness & -.015 & .025 & -.07 & .04 & .56 \\
\hline Emotional stability & $.091^{* *}$ & .026 & .04 & .14 & .001 \\
\hline Imagination & .040 & .031 & -.02 & .10 & .21 \\
\hline Extraversion $\times$ overreactivity & .018 & .021 & -.02 & .06 & .39 \\
\hline Extraversion $\times$ warmth & .002 & .019 & -.04 & .04 & .94 \\
\hline Benevolence $\times$ overreactivity & $.050^{* *}$ & .017 & .02 & .08 & .003 \\
\hline Benevolence $\times$ warmth & .021 & .020 & -.02 & .06 & .30 \\
\hline Conscientiousness $\times$ overreactivity & -.007 & .023 & -.05 & .04 & .77 \\
\hline Conscientiousness $\times$ warmth & -.033 & .021 & -.07 & .01 & .12 \\
\hline Emotional stability $\times$ overreactivity & -.040 & .022 & -.08 & .004 & .08 \\
\hline Emotional stability $\times$ warmth & .007 & .022 & -.04 & .05 & .75 \\
\hline Imagination $\times$ overreactivity & .015 & .025 & -.03 & .07 & .55 \\
\hline Imagination $\times$ warmth & .038 & .028 & -.02 & .09 & .18 \\
\hline
\end{tabular}

\section{Discussion}

The current study was designed to enhance knowledge of individual and proximal contextual predictors of general self-efficacy (GSE) in early adulthood (20-23 years). In addition to examining main effects of children's individual characteristics (Big Five personality traits; 9-12 years), and two types of parenting (warmth, overreactive discipline) by mothers and fathers on early adult GSE, we explored the extent to which children's individual personality characteristics moderated effects of childhood parenting on early adult GSE. We tested whether moderation effects provided support for diathesis stress or the differential susceptibility models of person-environment interactions. Results indicated that child emotional stability was associated with higher GSE eleven years later, but main effects of parental warmth and overreactive discipline were non-significant. Further, we found evidence of one interaction effect showing that children's benevolence functioned as a susceptibility marker in the longitudinal association between parental overreactivity and GSE. However, overall, the general lack of significant interaction effects is consistent with a main-effects only model. 


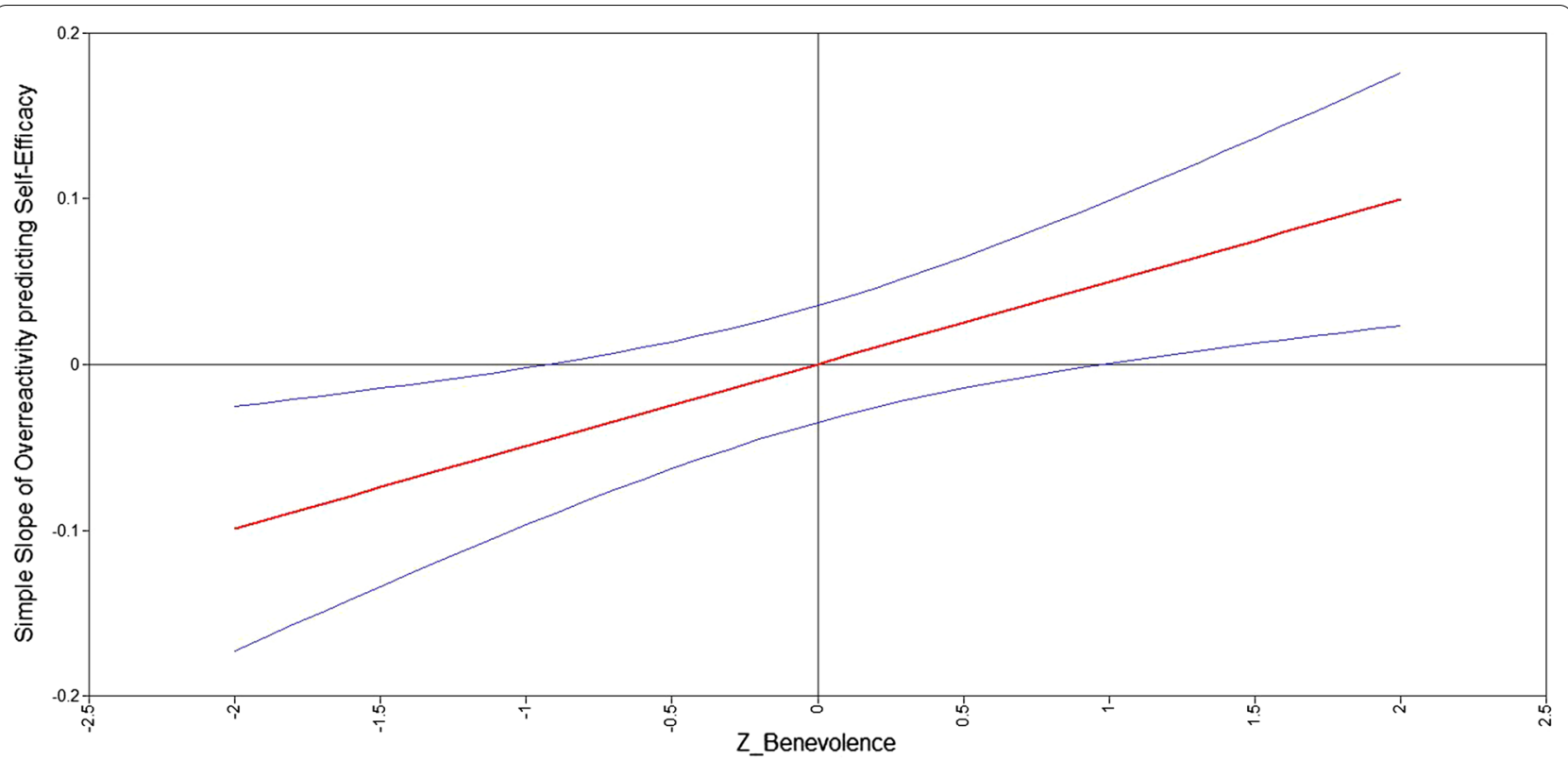

Fig. 2 The association between overreactivity and self-efficacy at all levels of benevolence. Note. When benevolence is below $-.09 S D$, higher levels of parental overreactivity are associated with lower the self-efficacy. When adolescents score higher than 1SD above the mean on benevolence, overreactivity is positively linked to self-efficacy

\section{Main effects of childhood personality and parenting on early adulthood GSE}

Regarding the main effects of mothers' and fathers' parenting and children's personality traits, this study found that children's emotional stability was associated with higher general self-efficacy eleven years later. That emotional stability is the most important predictor of selfefficacy is in line with the meta-analysis of Judge, Erez [31], examining associations among Big Five personality and general self-efficacy, and our study indicates that this holds across a long period of time. Emotional stability comprises, amongst others, the extent to which children are anxious (reverse-coded) and feel confident about themselves [46]. Our results suggest that this self-confidence in childhood may translate into feeling more efficacious about one's own actions and capabilities in early adulthood, eleven years later. Children who score low on emotional stability are more insecure and cope less effectively with stressors [63] which may result in lower self-efficacy over time. Given that GSE is an important correlate of a wide range of (developmental) outcomes [5, $64,65]$, knowing which individual characteristics are predictive of higher GSE may give direction to interventions aimed at improving early adult's general self-efficacy. Results from this study suggest that targeting children's feelings of anxiousness and self-confidence in interventions may have promising, long-term effects on their selfefficacy. Indeed, preliminary evidence for this hypothesis exists, with a 6-week school-based resilience intervention for 11-12-year-olds showing improvements in self-efficacy for all youth, and especially targeted the needs of children with negative affectivity [66]. Thus, especially for children low in emotional stability, such interventions might therefore in the long run improve their sense of self-efficacy.

Nevertheless, no other main effects of child personality, or of mothers' and fathers' parenting on early adults' GSE were found to be significant. These mostly non-significant results are inconsistent with theory and empirical work examining short-term effects of child personality and parenting on child development $[15,22$, 23]. The inconsistencies in the patterns of results may be due to the fact that the current study examined associations between constructs that were assessed more than a decade apart, and with a multi-informant design [i.e., different informants for the outcome (self-reports) versus predictor variables (parent-reports)]. That less significant longitudinal associations between personality characteristics and outcomes are found is in line with other work. Rioux, Castellanos-Ryan [67] for example reported statistically significant cross-sectional but no longitudinal relations between impulsivity and adolescence substance use.

\section{Moderation of parenting-GSE associations by personality}

Second, we explored to what extent associations between mothers' and fathers' overreactive discipline and warmth and young adults' GSE were moderated by children's big five personality dimensions. We found 
evidence for one interaction effect, which supported the differential susceptibility model. Children with relatively low levels of benevolence were more sensitive to an adverse environment, with high mother- and father-reported overreactive discipline being associated to less GSE in early adulthood for these children only. Whereas, high benevolent children seem to be protected from the negative effects of high parental overreactivity, with high parental overreactivity being associated with more GSE for these children only. On the one hand, this result suggests that children scoring low on benevolence appear particularly vulnerable to the adverse effects of overreactive discipline, and these adverse effects may be long-lasting. This result is in line with earlier research focusing on interactions between parenting and personality with different outcome measures, for example aggression and rule-breaking trajectories [68], externalizing behavior [69], adolescent alcohol use [70] and trajectories of anxious and depressive problems [39]. Children scoring low on benevolence generally are more irritable and egocentric, and less compliant. The results indicate that these personal dispositions may form a vulnerability for these children in combination with overruling and strict discipline of parents. An additional possibility is that children who are more irritable and less compliant evoke more overreactive parenting, suggesting a mediating role of overreactivity or a dynamic and reciprocal process between children's personality and parents resulting in more positive or negative developmental outcomes $[42,71]$.

In contrast, children scoring 'average' on benevolence appear not to be affected by mothers' and fathers' overreactive discipline in the long-term regarding their GSE. Rather surprisingly, children scoring high on benevolence reported higher GSE when their parents used more overreactive discipline and therefore seemed to be protected from the adverse effects of this parental practice. A possible explanation for this unexpected result is that children scoring high on benevolence are eager to obey their parents and that the strict discipline of their parents leads to more goal-driven behavior. This may result in higher levels of mastery and self-efficacy. Given that this is the first study to investigate long term effects of personality-parenting interactions and the inclusion of several interactions, future research should replicate this finding.

Consistent with our expectations, all main effects and interactions were similar (not statistically different) for (children of) mothers versus fathers. This pattern of results is in line with much research that employed stringent tests of parental gender differences [72, 73], and imply that generally, mothers and fathers are similarly important for their children's outcomes.

\section{Limitations and future directions}

Several limitations warrant caution in the interpretation of results. First, our study relied exclusively on questionnaire measures, which increases the risk of method bias. A related issue is the fact that parenting was only reported by the parents themselves. Levels of agreement between parent and child reports on parental behaviors are generally modest, with parents reporting more favorably than their children on parenting [74]. Therefore, a multimethod measurement strategy (e.g., the inclusion of observational measures) might result in more accurate assessment of parenting and children's individual differences and thus further strengthen the results.

Second, our sample consisted solely of Western European families, and results of this study cannot be directly generalized to other samples. Previous studies have shown that the impact of parenting differs across cultural contexts. For example, overreactive discipline was found to be stronger related to childhood psychopathology in collective cultures than in individualistic cultures [75]. Future studies should examine the (main and interactive) effects of children's individual personality characteristics and mothers' and fathers' parenting in samples with more diverse characteristics, not only in terms of ethnicity, but also, with regard to socio-economic status, family composition, and in families at-risk for child or parent psychopathology.

Third, our study is one of the first studies that examined prospective associations between childhood personality and parenting and emerging adulthood self-efficacy, through which we aimed to provide a more comprehensive picture of temporal associations. Nonetheless, it is generally considered to be ideal to also include the outcome measure at predictor time points. Such data could provide further insights into the directions of effects. Unfortunately, we only have self-efficacy available at one time point in emerging adulthood. In addition, parenting and personality interact with each other and shape each other at the same time [76]. Therefore, future research should also focus on the dynamic and reciprocal effects between parenting, child development, and children's individual characteristics, preferably using measurements assessed at different time-scales (e.g., day-to-day, monthly, and yearly assessments) [77, 78]. Lastly, in a period of 11 years several life-events can occur that affect adjustment over time. Such so-called interim effects, unobserved events that can occur during the measured time period, might influence the outcome measurements [79]. On the other hand, despite such possible life-events that differ per person and that could affect self-efficacy, this study found significant associations between childhood personality and early adulthood general selfefficacy. Future research should focus on the effect of 
life-events and on mechanisms that can explain the prospective associations among personality and self-efficacy.

\section{Conclusion}

The present study showed that childhood emotional stability is an important long-term predictor of self-efficacy, even into emerging adulthood. In addition, it was found that mothers' and fathers' overreactive discipline was related to self-efficacy eleven years later but only for children scoring either low or high on benevolence. Overall, results from our study suggest that child individual characteristics (emotional stability) may have long-lasting effects on children's self-efficacy. Moreover, the integration of individual differences in models of parenting effects may further improve our understanding of early adults' adjustment.

\section{Acknowledgements}

Not applicable.

\begin{abstract}
Authors' contributions
$M D$ and WVE were involved with the design and analyses and prepared and finished the second draft of the paper. VOdV was involved in every phase of the study, particularly the conception of the study, the study design, the preparation of data, the interpretation of analyses and the writing of the first draft of the manuscript; AR and AdH provided feedback and contributed to the writing of the paper. PP conceived the study, performed statistical analyses, and led the design and writing. All authors read and approved the final manuscript.
\end{abstract}

\section{Funding}

Not applicable.

\section{Availability of data and materials}

The datasets used and/or analyzed during the current study are available from the corresponding author on reasonable request.

\section{Declarations}

\section{Ethical approval and consent to participate}

Il procedures performed in studies involving human participants were in accordance with the ethical standards of the institutional research committee and with the 1964 Helsinki declaration and its later amendments or comparable ethical standards. The board of the Katholieke Universiteit Leuven approved the study (OT 98/12 ZKA 2922). This study is conducted in full compliance with pertinent international treaties, national laws, regulations and codes concerning research involving minors (adolescents), as well as privacy. The study protocol meets since the beginning in 1999 the requirements of the codes of conduct of pertinent professional associations, in particular of national and international psychological and behavioral associations. Given that neither interventions nor invasive actions are part of this study, the board of the Katholieke Universiteit Leuven approved this study and conforming the Belgian law no further approval was needed. The Belgian law on research with human subjects stipulates that a scientific research project is subject to formal ethical approval by a Medical-Ethical Committee if it is explicitly relevant to the medical science and experiments are used (Art. 1). In this project no medications or experiments are involved. Informed consent was obtained from all individual participants included in the study. At T1 (2004), when participants were minors, parents provided informant consent and at Wave 8, when participants were adult, they provided informed consent.

\section{Consent for publication}

Not applicable.

\section{Competing interests}

The authors declare no competing interests.

\section{Author details}

${ }^{1}$ Department of Psychology, Education and Child Studies, Erasmus School of Social and Behavioural Sciences, Erasmus University Rotterdam, PO Box 1738, 3000 DR Rotterdam, The Netherlands. ${ }^{2}$ Present Address: HYPE Centre of Expertise on Early Intervention for Borderline Personality Disorder, GGz Centraal, Amersfoort, The Netherlands. ${ }^{3}$ Present Address: Youz, Parnassia Psychiatric Institution, The Hague, The Netherlands.

Received: 6 April 2021 Accepted: 11 October 2021

Published online: 03 November 2021

\section{References}

1. Schwarzer R, Warner LM. Perceived self-efficacy and its relationship to resilience. In: Resilience in children, adolescents, and adults, Springer; 2013. p. 139-50.

2. Luszczynska A, Gutiérrez-Doña B, Schwarzer R. General self-efficacy in various domains of human functioning: evidence from five countries. Int J Psychol. 2005;40(2):80-9.

3. Bandura A. Self-efficacy: toward a unifying theory of behavioral change. Psychol Rev. 1977;84(2):191-215.

4. Caprara GV, Vecchione M, Alessandri G, Gerbino M, Barbaranelli C. The contribution of personality traits and self-efficacy beliefs to academic achievement: a longitudinal study. Br J Educ Psychol. 2011;81(Pt 1):78-96.

5. Burger K, Samuel R. The role of perceived stress and self-efficacy in young people's life satisfaction: a longitudinal study. J Youth Adolesc. 2017:46(1):78-90.

6. Pinquart M, Juang LP, Silbereisen RK. Self-efficacy and successful schoolto-work transition: a longitudinal study. J Vocat Behav. 2003;63(3):329-46.

7. Richardson M, Abraham C, Bond R. Psychological correlates of university students'academic performance: a systematic review and meta-analysis. Psychol Bull. 2012;138(2):353-87.

8. Caspi A, Roberts BW, Shiner RL. Personality development: stability and change. Annu Rev Psychol. 2005;56:453-84.

9. Costa PT Jr, McCrae RR, Löckenhoff CE. Personality across the life span. Annu Rev Psychol. 2019;70:423-48.

10. Power TG. Parenting dimensions and styles: a brief history and recommendations for future research. Child Obes. 2013;9:S14-21.

11. Maccoby E, Martin J. Socialization in the context of the family: parentchild interaction. In: Handbook of child psychology, vol. 4, socialization, personality, and social development. New York: Wiley; 1983. p. 1-101.

12. Zuckerman M. Diathesis-stress models. In: Zuckerman M, editor. Vulnerability to psychopathology: a biosocial model. Washington, DC: American Psychological Association; 1999. p. 3-23.

13. Belsky J, Pluess M. Beyond diathesis stress: differential susceptibility to environmental influences. Psychol Bull. 2009;135(6):885-908.

14. Loeb EL, Kansky J, Tan JS, Costello MA, Allen JP. Perceived psychological control in early adolescence predicts lower levels of adaptation into midadulthood. Child Dev. 2020;92:e158-72.

15. Reed K, Duncan JM, Lucier-Greer M, Fixelle C, Ferraro AJ. Helicopter parenting and emerging adult self-efficacy: implications for mental and physical health. J Child Fam Stud. 2016;25(10):3136-49.

16. Ryan RM, Deci EL. Self-determination theory: basic psychological needs in motivation, development, and wellness. New York: Guilford Publications; 2017

17. Sweet SN, Fortier MS, Strachan SM, Blanchard CM. Testing and integrating self-determination theory and self-efficacy theory in a physical activity context. Can Psychol. 2012;53(4):319.

18. McCabe JE. Maternal personality and psychopathology as determinants of parenting behavior: a quantitative integration of two parenting literatures. PsyB. 2014;140(3):722.

19. Soenens B, Deci EL, Vansteenkiste M. How parents contribute to children's psychological health: the critical role of psychological need support, development of self-determination through the life-course. Springer: 2017. p. 171-87.

20. Peterson GW. Family influences on adolescent development. In: Handbook of adolescent behavioral problems; 2005, Springer. p. 27-55. 
21. Prinzie P, Stams GJ, Dekovic M, Reijntjes AH, Belsky J. The relations between parents' Big Five personality factors and parenting: a metaanalytic review. J Pers Soc Psychol. 2009;97(2):351-62.

22. Swenson RR, Prelow HM. Ethnic identity, self-esteem, and perceived efficacy as mediators of the relation of supportive parenting to psychosocial outcomes among urban adolescents. J Adolesc. 2005;28(4):465-77.

23. Frank G, Plunkett SW, Otten MP. Perceived parenting, self-esteem, and general self-efficacy of Iranian American adolescents. J Child Fam Stud. 2010;19(6):738-46.

24. Patterson GR. Coercive family process. Eugene: Castalia Publishing Company; 1982

25. Seegan PL, Welsh KL, Plunkett SW, Merten MJ, Sands T. Neighborhood, parenting, and individual qualities related to adolescent self-efficacy in immigrant families. Fam Consum Sci Res J. 2012;40(4):348-60.

26. Givertz M, Segrin C. The association between overinvolved parenting and young adults'self-efficacy, psychological entitlement, and family communication. Commun Res. 2012;41(8):1111-36.

27. van Ingen DJ, Freiheit SR, Steinfeldt JA, Moore LL, Wimer DJ, Knutt AD, et al. Helicopter parenting: the effect of an overbearing caregiving style on peer attachment and self-efficacy. J Coll Couns. 2015;18(1):7-20.

28. Zakiei A, Vafapoor H, Alikhani M, Farnia V, Radmehr F. The relationship between family function and personality traits with general self-efficacy (parallel samples studies). BMC Psychol. 2020;8(1):1-11.

29. Keshavarz S, Mounts NS. Perceived parenting style of fathers and iranian adolescents' self-efficacy: the moderating role of gender and education. J Genet Psychol. 2017;178(5):281-90.

30. Shiner R, Caspi A. Personality differences in childhood and adolescence: measurement, development, and consequences. J Child Psychol Psychiatry. 2003;44(1):2-32

31. Judge TA, Erez A, Bono JE, Thoresen CJ. Are measures of self-esteem, neuroticism, locus of control, and generalized self-efficacy indicators of a common core construct? J Pers Soc Psychol. 2002;83(3):693-710.

32. Maddux JE, Kleiman EM. Self-efficacy: a foundational concept for positive clinical psychology. New York: Wiley; 2016.

33. Stajkovic AD, Bandura A, Locke EA, Lee D, Sergent K. Test of three conceptual models of influence of the big five personality traits and self-efficacy on academic performance: a meta-analytic path-analysis. Pers Individ Dif. 2018;120:238-45.

34. Brown D, Cinamon DRGJJfE, Guidance V. Personality traits' effects on self-efficacy and outcome expectations for high school major choice. Int J Educ Vocat Guid. 2016;16(3):343-61.

35. Schmitt $N$. The interaction of neuroticism and gender and its impact on self-efficacy and performance. Hum Perform. 2007;21(1):49-61.

36. Sameroff A. A unified theory of development: a dialectic integration of nature and nurture. Child Dev. 2010;81(1):6-22.

37. Lianos PG. Parenting and social competence in school: the role of preadolescents' personality traits. J Adolesc. 2015;41:109-20.

38. de Haan AD, Prinzie P, Dekovic M. How and why children change in aggression and delinquency from childhood to adolescence: moderation of overreactive parenting by child personality. J Child Psychol Psychiatry. 2010;51(6):725-33.

39. Prinzie P, van Harten LV, Dekovic M, van den Akker AL, Shiner RL. Developmental trajectories of anxious and depressive problems during the transition from childhood to adolescence: personality $x$ parenting interactions. Dev Psychopathol. 2014;26(4 Pt 1):1077-92.

40. Belsky J, Bakermans-Kranenburg MJ, van ljzendoorn MH. For better and for worse. Curr Dir Psychol Sci. 2016;16(6):300-4.

41. Morgan JK, Shaw DS, Olino TM. Differential susceptibility effects: the interaction of negative emotionality and sibling relationship quality on childhood internalizing problems and social skills. J Abnorm Child Psychol. 2012;40(6):885-99.

42. Prinzie $P$, Onghena P, Hellinckx W, Grietens $H$, Ghesquiere P, Colpin H. The additive and interactive effects of parenting and children's personality on externalizing behaviour. Eur J Pers. 2003;17(2):95-117.

43. Arnold DS, O'Leary SG, Wolff LS, Acker MM. The Parenting Scale: a measure of dysfunctional parenting in discipline situations. Psychol Assess. 1993;5(2):137

44. Prinzie P, Onghena P, Hellinckx W. Reexamining the Parenting Scale. Eur J Psychol Assess. 2007;23(1):24-31.
45. Robinson CC, Mandleco B, Olsen SF, Hart CH. Authoritative, authoritarian, and permissive parenting practices: development of a new measure. Psychol Rep. 1995;77(3):819-30.

46. Mervielde I, De Fruyt F, editors. Construction of the hierarchical personality inventory for children (HiPIC). In: Personality psychology in Europe proceedings of the eight European conference on personality psychology; 1999; Tilburg: Tilburg University Press.

47. Teeuw B, Schwarzer R, Jerusalem M. Dutch adaptation of the general perceived self-efficacy scale. 1994.

48. Luszczynska A, Scholz U, Schwarzer RJTJ. The general self-efficacy scale: multicultural validation studies. J Psychology. 2005;139(5):439-57.

49. Muthén LK, Muthén BO. Mplus user's guide. 8th edn. Los Angeles, CA: Muthén \& Muthén; 1998-2017.

50. Cohen J, Cohen P, West SG, Aiken LS. Applied multiple correlation/ regression analysis for the social sciences. 3rd ed. Hillsdale: Erlbaum; 2003.

51. Asparouhov T, Muthen B, editors. Computationally efficient estimation of multilevel high-dimensional latent variable models. In: Proceedings of the 2007 JSM meeting in Salt Lake City, Utah, Section on Statistics in Epidemiology; 2007: Citeseer.

52. Muthen BO, Satorra A. Complex sample data in structural equation modeling. Sociol Methodol. 1995. https://doi.org/10.2307/271070.

53. Roisman GI, Newman DA, Fraley RC, Haltigan JD, Groh AM, Haydon KC. Distinguishing differential susceptibility from diathesis-stress: recommendations for evaluating interaction effects. Dev Psychopathol. 2012;24(2):389-409.

54. Johnson PO, Neyman J. Tests of certain linear hypotheses and their application to some educational problems. Stat Res Memoirs. 1936;1:57-93.

55. Hayes AF, Matthes J. Computational procedures for probing interactions in OLS and logistic regression: SPSS and SAS implementations. Behav Res Methods. 2009;41(3):924-36.

56. Clavel F. Advanced topics: plotting better interactions using the JohnsonNeyman technique in Mplus 2015. Available from: https://clavelresearch. wordpress.com/2015/03/23/advanced-topics-plotting-better-interactio ns-using-the-johnson-neyman-technique-in-mplus/.

57. Aiken LS, West SG, Reno RR. Multiple regression: testing and interpreting interactions. Thousand Oaks: Sage Publications; 1991.

58. Del Giudice M. Statistical tests of differential susceptibility: performance, limitations, and improvements. Dev Psychopathol. 2017;29(4):1267-78.

59. Del Giudice M. The evolution of interaction shape in differential susceptibility. Child Dev. 2017;88(6):1897-912.

60. Hu L, Bentler PM. Cutoff criteria for fit indexes in covariance structure analysis-conventional criteria versus new alternatives, structural equation modelling. Multidiscip J. 1999;6(1):1-55.

61. Browne MW, Cudeck R. Alternative ways of assessing model fit. In: Bollen KA, Long JS, editors. Testing structural equation models. Newbury Park: SAGE; 1993. p. 445-55.

62. Satorra A, Bentler PM. A scaled difference Chi-square test statistic for moment structure analysis. Psychometrika. 2001;66(4):507-14.

63. Carver CS, Connor-Smith J. Personality and coping. Annu Rev Psychol. 2010;61:679-704.

64. Caprara GV, Barbaranelli C, Pastorelli C, Cervone D. The contribution of self-efficacy beliefs to psychosocial outcomes in adolescence: predicting beyond global dispositional tendencies. Pers Individ Dif. 2004;37(4):751-63.

65. Cattelino E, Testa S, Calandri E, Fedi A, Gattino S, Graziano F, et al. Selfefficacy, subjective well-being and positive coping in adolescents with regard to Covid-19 lockdown. Curr Psychol. 2021. https://doi.org/10. 1007/s12144-021-01965-4.

66. Sabin C, Bowen AE, Heberlein E, Pyle E, Lund L, Studts CR, et al. The impact of a universal mental health intervention on youth with elevated negative affectivity: building resilience for healthy kids. Contemp School Psychol. 2021. https://doi.org/10.1007/s40688-021-00388-z.

67. Rioux C, Castellanos-Ryan N, Parent S, Vitaro F, Séguin JR. The interactive effects of parental knowledge with impulsivity and sensation seeking in adolescent substance use. Child Psychiatry Hum Dev. 2019;50(1):95-107.

68. Becht Al, Prinzie P, Dekovic M, van den Akker AL, Shiner RL. Child personality facets and overreactive parenting as predictors of aggression and rule-breaking trajectories from childhood to adolescence. Dev Psychopathol. 2016;28(2):399-413. 
69. Prinzie $P$, Onghena $P$, Hellinckx W, Grietens $H$, Ghesquière $P$, Colpin $H$. The additive and interactive effects of parenting and children's personality on externalizing behaviour. Eur J Pers. 2020;17(2):95-117.

70. Rioux C, Castellanos-Ryan N, Parent S, Vitaro F, Tremblay RE, Seguin JR. Differential susceptibility to environmental influences: Interactions between child temperament and parenting in adolescent alcohol use. Dev Psychopathol. 2016;28(1):265

71. Yan N, Ansari A, Peng P. Reconsidering the relation between parental functioning and child externalizing behaviors: a meta-analysis on childdriven effects. J Fam Psychol. 2020;35:225.

72. Janssen HJ, Eichelsheim VI, Deković M, Bruinsma GJ. Sex differences in longitudinal pathways from parenting to delinquency. Eur J Crim Policy Res. 2017;23(4):503-21.

73. Prinzie $P$, van der Sluis $C M$, de Haan AD, Dekovic M. The mediational role of parenting on the longitudinal relation between child personality and externalizing behavior. J Pers. 2010;78(4):1301-23.

74. Korelitz KE, Garber J. Congruence of parents' and children's perceptions of parenting: a meta-analysis. J Youth Adolesc. 2016;45(10):1973-95.

75. Tahmouresi N, Schmitz J, Bender C, Tuschen-Caffier B. The impact of culture on parenting and psychopathology in children: a comparative study between Iran and Germany. Iran J Psychiatry Behav Sci. 2017;11(1):e4178.
76. Lengua LJ, Kovacs EA. Bidirectional associations between temperament and parenting and the prediction of adjustment problems in middle childhood. J Appl Dev Psychol. 2005;26(1):21-38.

77. Dieleman LM, Soenens B, Vansteenkiste M, Prinzie P, Laporte N, De Pauw SSW. Daily sources of autonomy-supportive and controlling parenting in mothers of children with ASD: the role of child behavior and mothers' psychological needs. J Autism Dev Disord. 2019;49(2):509-26.

78. Mabbe E, Vansteenkiste M, Brenning K, De Pauw S, Beyers W, Soenens B. The moderating role of adolescent personality in associations between psychologically controlling parenting and problem behaviors: a longitudinal examination at the level of within-person change. Dev Psychol. 2019;55(12):2665

79. De Lange AH, Taris TW, Kompier MA, Houtman IL, Bongers PM. "The very best of the millennium": longitudinal research and the demand-control(support) model. J Occup Health Psychol. 2003;8(4):282.

\section{Publisher's Note}

Springer Nature remains neutral with regard to jurisdictional claims in published maps and institutional affiliations.
Ready to submit your research? Choose BMC and benefit from:

- fast, convenient online submission

- thorough peer review by experienced researchers in your field

- rapid publication on acceptance

- support for research data, including large and complex data types

- gold Open Access which fosters wider collaboration and increased citations

- maximum visibility for your research: over $100 \mathrm{M}$ website views per year

At BMC, research is always in progress.

Learn more biomedcentral.com/submissions 